\title{
YEREL VE ULUSAL ÖLÇEKTE “AKILLI KENT” PERSPEKTIFI
}

\author{
Abdullah ÖZDEMiR ${ }^{1}$, Arzu ÖZDEMIR ${ }^{2}$ \\ ${ }^{1}$ Çevre Yüksek Mühendisi Ordu Büyükșehir Belediyesi CBS Şube Müdürlüğü, abdullahozdemir@ ordu.bel.tr \\ ${ }^{2}$ Harita Mühendisi. Ordu Büyükșehir Belediyesi Harita Zemin Șube Müdürlüğü, arzu.ozdemir@ordu.bel.tr
}

\section{ÖZET}

Daha kaliteli bir yaşam, daha iyi eğitim, sağlık hizmetlerine daha kolay erişim ve daha fazla iş olanakları gibi beklentilerle hızla artan köyden kente göç oranları çarpıcı boyutlara ulaşmıştır. Birleşik Milletler kentleşme projeksiyonlarına göre dünya genelinde günde ortalama 200.000 kişinin kentlere göç ettiği görülmektedir. Artan göç olaylarl, hem göç veren hem de göç alan kentleri önemli ölçüde etkilemektedir. (Kalkınma Bakanlığ

Kentlerin yüz ölçümü ve nüfusundaki değişimlerin yanı sira modernleşme sürecinde yaşanan demografik geçiş, küresel ısınma, yeni nesillerle birlikte gelişen ve değişen beklentiler, kentlerin ihtiyaçlarını şekillendirmektedir. Kısıtll kaynaklarla bu ihtiyaçların sürdürülebilir bir biçimde karşılanması alışılageldik geleneksel yöntemlerle çoğu zaman mümkün olamamaktadır. Artan sorunların giderilmesi ihtiyaçların karșılanabilmesi arayıșının bir sonucu olarak ortaya çıkan "Akıllı Kent" kavramı geleneksel anlayışlarla çözülmek bir yana daha da karmaşılklaşan sorunların çözümü için bir umut olmuştur.

Dünyadaki gelişmelere paralel olarak "akıllı kent” yaklaşımı, ülkemizde de son derece ilgi çeken günden güne popülerleşen bir kavram, adeta bir "moda" olmuştur.

Çok katmanlı her kavramda olduğu gibi kabul gören tek bir tanımı yapılamayan akıllı kent kavramının kullanımı yaygınlaşmış ve farklı kişi ve gruplar tarafindan pek çok farklı anlamda kullanılır olmuştur.

Akıllı kent; "bilişsim teknolojilerinden yararlanılarak kent varlıklarını ve kaynaklarını bütünleştiren kentsel gelişim vizyonu ve her kentin kendi ihtiyacına göre şekillenen bir yolculuktur" ifadesi çoğunlukla kabul gören kapsayıcı bir tanım olarak değerlendirilmektedir.

Artan kentsel sorunlar, akıllı kent çözü̈mlerini yerel yönetimler için zorunlu bir ihtiyaca dönüştürmüşü̈r. Yerel yönetimler artan nüfusla gelen trafik, ulaşım, vatandaş memnuniyeti, çevre yönetimi, güvenlik vb. güçlükleri teknoloji ile aşmanın yollarına odaklanmıştır.

Belediyelerin ölçeği değiştikçe sorunları ve sorunların öncelikleri de değişmekle beraber hizmet sunumunda teknoloji ile fark yaratma anlayışı hâkimdir. Bir diğer ifadeyle, yerel yönetimler öncelikli çözüm geliştirme ihtiyaçları olan hizmet alanlarında teknolojiyi en kritik çözüm aracı olarak görmektedirler.

Ülkemizdeki akıllı kent çalışmaları için farklı bir perspektif sunma amacıyla kaleme alınan bu çalışmada dünyadaki başarılı akıllı kent uygulamaları incelenmiş, ülkemizde kavramsal ve yönetsel yaklaşımlar ile daha önce benzer durumlarda yaşanmış proje deneyimleri eleştirel bir bakış açısıyla derlenmeye çalışılmıştır.

Görülmek, duyulmak istenmeyen gerçeklerin de dikkate alındı̆̆g, hamasetin değil bilimsel yöntemlerin benimsendiği gerçekçi bir vizyon, devamında ulaşılabilir hedeflerin belirlendiği sürekli bir yolculuk olan, "akıllı kent" idealinin ülkemizde de başarılyla uygulanabilmesi için yapılması ve yapılmaması gerekenlerin neler olduğu, incelenen örnekler üzerinden eleştirel bir perspektifle sunulmaya çalışılmıştır.

Çalışmamızda Kopenhag, Barselona, Seul, Singapur, Berlin, New York, Londra, Gujarat, San Francisco gibi kentlerdeki akıllı kent uygulamaları incelenmiş, başta yaşadı̆̆ımız Ordu ili olmak üzere, ülkemize nasıl uyarlanması gerektiği konusunda yararlı olacağına inandı̆̆ımız çıkarımlarda bulunulmuştur.

Tüm başarılı uygulamaların ortak paydasının, gerçek zamanlı veri akışıyla beslenen ve odağında insanın olduğu Coğrafi Bilgi Sistemi altyapısı olduğu görülmüştür.

Başarılı bir akıllı kent uygulamasının, tekil teknolojik çözümlerden ziyade bütünsel bir bakış açısı gerektiren bütüncül ama özgün bir yaklaşımla mümkün olabileceği sonucuna varılmıştır.

Ülkemizde sıklıkla görmeye alıştığımız tek merkezden (Ankara) yönetilmeye çalışılan toptancı anlayışlar yerine, her kentin önceliklerini, güçlü ve zaylf yönlerini dikkate alan ve o kente özgü olan yaklaşımların, konulan hedeflere ulaşmada temel hareket noktası olduğu de ğerlendirilmiştir.

Anahtar Sözcükler: sk1llı kent, koordinasyon, büyük veri, coğrafi bilgi sistemleri.

\section{ABSTRACT}

\section{LOCAL AND NATIONAL SCALE OF "SMART CITY" PERSPECTIVE}

Rapidly growing rates of migration from peasants to cities have reached striking proportions, such as better quality of life, better education, easier access to health services and more job opportunities. When the United Nations urbanization projections are evaluated, it is observed that an average of 200,000 people emigrated to cities worldwide on a daily basis. Increased migration rates affect both immigrant and immigrant cities. (Kalkınma Bakanlı̆gl, 2013)

Demographic transition, global warming factors, new generations of emerging and changing expectations shape the needs of the cities, as well as the demographic transition in the process of modernization as well as the changes in the urban surface 
and population. Meeting these needs in a sustainable way with limited resources will be possible with innovative and intelligent solutions.

The concept of "Smart City", which emerged as a result of these searches, has attracted a great deal of attention with successful applications argued at academic level over 10 years.

Parallel to these developments in the world, our country has become a very popular concept in the day, which is very interesting in our country. It seems that this term, which does not have a generally accepted definition as it is in almost every multi-layered concept, is becoming increasingly widespread and used by different stakeholders in different meanings.

For smart cities, a general definition will cover many different approaches and understandings; "The vision of urban development that integrates urban assets and resources with the use of information technology, and each city is a journey shaped by its own needs".

Intelligent urban solutions have become a necessity for local governments. Local governments have been increasing traffic, transportation, citizen satisfaction, environmental management, security and so on. focusing on ways to overcome difficulties with technology.

As the scale of the municipalities changes, the problems and priorities of the problems change, and the understanding of making a difference with technology is prevalent in service delivery. In other words, local governments view technology as the most critical solution in their service areas where priority solution development needs exist.

In this study, which was taken to provide a different perspective for smart city studies in our country, successful smart city applications in the world were examined and conceptual and managerial approaches in our country and project experiences experienced in similar situations were tried to be compiled with a critical point of view.

In our work, smart city applications in cities such as Copenhagen, Barcelona, Seoul, Singapore, Berlin, New York, London, Gujarat and San Francisco were examined and found out for our country applications, especially in the province of Ordu where we lived.

It has been seen that the common stake of all successful applications is the Geographic Information System infrastructure that is fed by real-time data flow and is the human being in its focus.

A successful intelligent urban practice has come to the conclusion that a holistic approach, which requires a holistic view of individual technological solutions, is possible.

Keywords: smart city, coordination, big data, geographic information systems

\section{GİRIŞ}

Sürücüsüz araçlardan uzaktan yönetilebilen ev ve ofislere, suç oluşmadan tahmin edebilen ve önlem alabilen güvenlik sistemlerinden hastaneye gitmeden tıbbi teşhis ve tedavinin yapılabildiği uygulamalara, akı1lı kent çözümlerinin popülaritesi her geçen artmaktadır. (Ulusoy, 2017)

Akıllı kent, şehrin daha yaşanabilir, daha sürdürülebilir ve daha verimli olması amacıyla bilgi iletişim teknolojilerinin sağladığı çözümleri;

$>$ Odağına insanı alarak,

$>$ İlgili tüm paydaşların ve kurumların sahipliğinde,

$>$ Kişisel verinin gizliliği ve diğer etik kuralları ihlal etmeden,

> Katılımcı ve şeffaf bir şekilde uygulayabilen,

$>$ Kendini sürekli geliştiren ve öğrenen kenttir. (Boren,2013)

\subsection{Akıllı Kent Bileşenleri}

Şekil 1. Akıllı Kentlerin Temel Bileşenleri (Türkiye Bilişsim Vakfi, 2016).

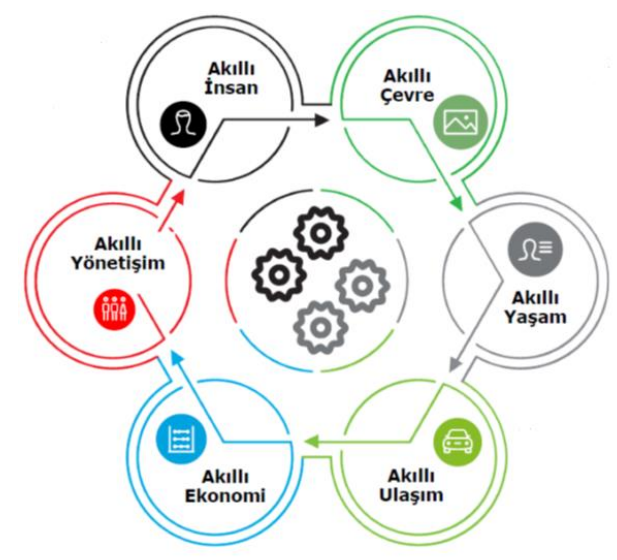

1. Ak1llı İnsan,

2. Akıllı Yönetişim,

3. Akıllı Yaşam,

4. Ak1llı Ekonomi,

5. Akıllı Ulaşım,

6. Akıllı Çevre

Barınma, güvenlik, sağlık, eğitim, boş zaman faaliyetleri gibi ihtiyaçların kapsamının teknolojiyle beraber belirlenmekte, sosyal bütünlüğün sağlanması amaçlamaktadır.

Kaldıraç etkisiyle mevcut kaynaklar daha etkin kullanılmakta, finansman ve insan kaynaklarına veya zamana dair darboğazlar aşılmaktadır. Toplu taşıma altyapısının en optimal haliyle kullanılması sayesinde trafik sıkışıklığı ve hava kirliliği gibi kentlerin temel problemlerinin azalması hedeflenmektedir. Teknoloji yardımıyla çevre ve doğanın 
sürdürülebilirliği sağlanabilmekte, yeşil alanlar ve su kaynakları kontrol edilebilmektedir. İnsanlar, sosyal hayata daha çok katılmakta, çoğulculuk ve kent kültürü yaşam boyu devam eden bir öğrenme sürecine dönüşmektedir. Yaratıcılık ve açık fikirlilik teşvik edilmektedir. Karar vericiler, teknolojiyle tüm paydaşların çıkarlarını göz önünde bulundurup kaynakların daha akıllı bir şekilde kullanılarak uzun vadeli toplumsal faydanın sağlanması için çalışacaktır. (Chourabi, 2012)

\subsection{Temel Kavramlar 1.2.1 Nesnelerin İnterneti (IoT)}

Nesnelerin İnterneti (IoT- Internet of Things) sosyal yaşantımızda kullandığımız nesnelerin bir takım veriler üretmesini ve bu verileri başka nesnelere veya sistemlere aktarmasını sağlayan bir teknolojidir. Yani, nesnelerin insan müdahalesi olmadan, kendi aralarında belirli protokoller aracıllğı ile iletişim kurmasıyla oluşan veri ağıdır. IoT, herhangi bir kişinin, herhangi bir şeyin, herhangi bir zamanda, herhangi bir yerde, herhangi bir hizmet ve herhangi bir ağ ile birbirleri ile bağlanmış olduğu bir kümeye yansıtan bir kavram olarak tanımlanabilmektedir. IoT, bütün iş dünyasını etkileyebilecek gelecek nesil teknolojilerde yeni bir yaklaşımdır ve günümüzdeki internet altyapısına akıllı cihazların ve nesnelerin tek tek tanımlanarak, bu cihazların birbiri ile bağlantılı olması şeklinde ifade edilmektedir. (Boren,2013) Böylelikle, makineden makineye (M2M) senaryoları sağlayacak şekilde cihazların, sistemlerin ve servislerin bir- birleri ile ileri düzeyde bağlantılı olması sağlanarak daha fazla fayda sağlanması amaçlanmaktadır. (Chourabi, 2012) Bu nedenle, otomasyon ile ilgili her alanda IoT' den bahsedilebilmektedir. IoT platformu; akıllı şehirler, trafik sıkışıklığı, atık yönetimi, yapısal sağlık, güvenlik ve acil servisler, lojistik, perakende satış, endüstriyel kontrol gibi oldukça geniş ve farklı bir uygulama yelpazesi için uygun çözümler sunabilmektedir. (A.B.M. Shawkat, 2013)

\subsubsection{Sensör}

İnsanların yerine çevremizdeki fiziksel ortam (sıcaklık, basınç, uzaklık vb.) değişikliklerini algılayan cihazlara "sensör" denir. Bir diğer adı da algılayıcılar yani duyargalardır. Fiziksel ortamla elektrik - elektronik cihazları birbirine bağlayan bir köprü görevi gören sensörlerin ilk üretim amacı aydınlatma iken günümüzde kullanılmadığ alan yok gibidir. Sensörler, akıllı telefonlar - tabletler, akıllı TV'ler, bilgisayarlar, arabalar, kapılar, aydınlatma sistemleri, hatta klozetlere varıncaya değin, hayatımıza nüfuz etmişlerdir.

Bir duyu organı gibi görev yaparak dijital çağda hayatımızı kolaylaştıran sensörlerden bazılarını; Pasif Infrared (PIR), Yüksek frekans (radar),Akıllı Telefon - Tablet - TV Sensörleri, El Hareketi Yakınlık Sensörü, Hareket Sensörü, Jiroskop, Jeomanyetik Sensör, Smart Interaction, Park - Far - Yağmur Sensörü, şeklinde sıralamak mümkündür. (Harrison, 2010)

\subsubsection{Büyük Veri (Big Data)}

Büyük Veri (Big Data) çalışma tablolarından veri tabanlarına, sunuculardan cloud servislere kadar toplanılmış her türlü veriyi kapsar. Büyük veri internette ve veri tabanlarında yapılan tüm paylaşımlar, fotoğraf arşivleri, log dosyaları (internette kaydı tutulan tüm hareketler) gibi farklı alanlardan elde edilen tüm verilerin analiz edilerek fayda sağlanabilecek hale getirilmesidir. (Anttiroiko, 2013)

Dünyadaki bilginin miktarı, toplanma hızı ve hareketliliği her geçen yıl katlanarak artmaktadır Öyle ki; tüm insanlık tarihi boyunca yaratılan toplam verinin çok daha fazlası geçtiğimiz 2 senede üretilmiştir. Veri artışı bu şekilde devam ettiğinde 2020 yılında yeryüzündeki her bir insan için saniyede ortalama 1,7 Megabaytlık veri akışının oluşacağı öngörülmektedir. (ITÜU Vakfi Dergisi, 2017)

\subsection{Akıllı Kentler ve Yerel Yönetimler}

Akıllı kent çözümleri yerel yönetimler için lüksten öte, bir ihtiyaca dönüşmüş durumdadır. Yerel yönetimler artan nüfusla gelen trafik, ulaşım, vatandaş memnuniyeti, çevre yönetimi, güvenlik vb. güçlükleri teknoloji ile aşmanın yollarına odaklanmıştır. Belediyelerin ölçeği değiştikçe sorunları ve sorunların öncelikleri de değişmekle beraber hizmet sunumunda teknoloji ile fark yaratma anlayışı hâkimdir. Bir diğer ifadeyle, yerel yönetimler öncelikli çözüm geliştirme ihtiyaçları olan hizmet alanlarında teknolojiyi en kritik çözüm aracı olarak görmektedirler. Yerel yönetimler dijitalleşme anlamında ciddi mesafe kat etmektedir. İletişim sağlayıcı firmalar tarafından yapılan dijitalleşme endeksi sonuçları da belediyelerin "yarına hazır" olma yolunda belli bir altyapıyı hızlı bir şekilde oluşturma gayreti içinde olduklarını göstermektedir. Ancak halen gidilecek önemli bir yol ve Türkiye için yakalanacak önemli firsatlar bulunmaktadır. Bu yolculukta rehberlik yapacak bir yol haritasına ihtiyaç duyulduğu görülmektedir. (Türkiye Bilişim Vakfi, 2016) 


\subsection{Başarılı Akıllı Kent Uygulamalarında Öne Çıkan Etmenler}

$>$ Net bir vizyon

$>$ Kamu - özel işbirliği

$>$ Entegre organizasyon

$>$ Etkin akıllı kent platformu

$>$ Vatandaş katılımı

$>$ Destekleyici teknoloji

$>$ Risk yönetimi

$>$ Sosyal kapsayıcılık

$>$ Proje yaygınlaştırma becerisi

$>$ Destekleyici yasal çerçeve

\subsection{Akıllı Kentin Temel Sağlayıcıları}

İnsanı merkezine alan akıllı kentler üçlü sacayağı üzerinde yükselirler. Akıllı kentlerin çalışabilmesi için temel sağlayıcılar nitelikli insan kaynağı, ilgili mevzuat düzenlemeleri ve mevzuat altyapısı ile teknoloji çözümleridir. Başarılı akıllı kent yolculuklarının çalışma mekanizması bu yapının sağlam kurgulanması, kent vizyonuna yönelik olarak ilgili kilit performans göstergelerin belirlenerek akıllı kent stratejilerinin ve yol haritalarının bütünsel bir şekilde oluşturulmasına dayanmaktadır. (Harrison, 2010)

$\checkmark \quad$ Sistemlerin kullanıcıları ve uygulayıcıları: Kent sakinleri, turistler, vatandaşlar, sistem uygulayıcıları ve yöneticiler, STK üyeleri

$\checkmark$ Üst politika belgeleri, akıllı kentler vizyon, misyon ve stratejileri, uygulama ve denetim hakkının sağlandığ 1 birincil ve ikincil mevzuat

$\checkmark$ Yeni nesil bilgi iletişim sistemleri: nesnelerin interneti, mobil ve dijital platformlar, büyük veri, açık veri, robotlar, sürücüsüz taşıtlar vb.

\subsection{Başarılı Akıllı Kent Uygulama Örnekleri}

Akıllı kent kavramının literatürde benzer amaçlarla kullanılan ancak genelde sadece teknoloji odaklı olan kavramlardan ayıran ana unsur akıllı kent kavramının teknolojinin yanı sıra insanı ve kurumları merkezine almasıdır. Bu doğrultuda altı temel akıllı kent bileşeni tanımlanmaktadır. Bu bileşenler çeşitli sosyoekonomik teorilere göre tanımlanan faktörleri gözeterek başta Avrupa Birliği’nde sonra çeşitli diğer ülkelerde kentlerin ne kadar akıllı olduğunu ölçme ve değerlendirme amacıyla kullanılmaktadır. Bu çalışmada Global 2025 Projesi Kapsamında seçilmiş olan kentlerden Kopenhag, Barselona, Seul, Singapur, Berlin, New York, Londra, Gujarat, San Francisco uygulamaları incelenerek benzerlikleri, farklılıkları ve özgün yanları ortaya konmaya çalışılmıştır. Kimi kentler teknolojide lider olma, ekonomik yatırımlar için cazibe merkezi olma gibi ideallerle sıfırdan inşa edilirken kimileri binlerce yıllık tarihine istinaden yüzyıllardır faaliyet gösteren altyapılarını güncelleyerek yarının ihtiyaçlarına cevap vermeye çalışmaktadır. Örneğin akıllı kent yolculuğu devam eden New York, Londra, Berlin, Barselona, Kopenhag, Viyana gibi kentler farkı seviyelerde olgunluk kazanırken özellikle Uzak Doğu'da akıllı kent temasıyla oluşturulan kentler göze çarpmaktadır. Güney Kore'de, başkent Seul'den 65km ötede 1slah edilen arazi üzerine kurulan Songdo veya Çin ve Singapur arasında işbirliğini artırması amaçlanarak kurulan Tianjin kentleri yeni kurulan bölgeler arasındadır. Dolayısıyla akıllı kent çözümleri, farklı yoğunlukta nüfusları barındıran hem tarihi zenginliğini yitirmeden geleceğe hazırlanmaya çalışan kentlere hem de yoktan inşa edilen kentlere hizmet etmektedir.

\subsubsection{Kopenhag}

Karbon salınımsız bir başkent olmak, mavi ve yeşil bir başkent olmak, temiz ve sağlıklı bir kent olmak ve dünyada bisikletçilerin başkenti olmak hedefiyle yola çıkan Kopenhag için Akıllı Kent düşüncesi, kenti herkes için daha yaşanabilir ve sürdürülebilir bir yer haline getirmeye yardımcı olan bir araç gibidir. Kopenhag, sürdürülebilir ve yaşanılır bir kent olmaya çalışmaktadır ve bunu gerçekleştirmek için birçok akıllı kent projesi oluşturmuştur. Tüm 
akılll çözümler, 2025'e kadar dünyada ilk karbonsuz kent olma vizyonuna uygun olarak sürdürülebilir sonuçlar sağlayacak şekilde tasarlanmıştır.

Kopenhag'ın kent vizyonunu destekleyen 3 kilit bileşeni vardır. Bunlar; iyi tasarlanmış kentsel planlama, akıllı kent aracı ve pazarlama ve markalaşmadır.

Kopenhag'da, AB projelerine katılım, Danimarka'nın diğer kentleriyle ortaklık ve Singapur'la işbirliği ile desteklenen bir bilgi paylaşımı kültürü vardır.

\subsubsection{Singapur}

Akıllı kent planının vizyonu, bilgi-iletişim teknolojisini (BİT) büyütmek, BİT başlıca ekonomik sektörlerin rekabetçiliğini geliştirmek ve bağlantılı bir toplum inşa etmek ve bunların hepsini gelecek on yılda vatandaşların yaşamını iyileştirmek için kullanmaktadır.

Singapur'daki akıllı kent fikri 10 yıldan uzun süredir gündemdedir. Esasen Singapur, insanların sosyal nokta olmasına, Gezegenin çevre olmasına ve Karların ekonomik olarak uygulanabilir olmasına odaklanmaktadır.

Singapur, hükümetin iyi ekonomi politikalarına, son derece nitelikli bir iş gücüne, yüksek üretkenliğe ve son teknolojiye dayanan, büyümenin motoru olarak inovasyona odaklanan gelişmiş bir ülkedir ve bu nedenle Ar-Ge' ye yoğun yatırım yapmaktadır. Singapur'da geleceğe giden akıllı kent, tüm ülkeyi her alanda sağlık, eğitim, ulaşım, yönetim, bina ve sosyal altyapıda birbirine bağlayabilecektir. Singapur'da, akıllı şehri geliştirmek adına girişimleri destekleyen güçlü ilkeler ve teknolojinin gelişmesi için hem ulusal hem de uluslararası özel şirketlerle fonlar ve ortak teşebbüsler anlamında güçlü bir hükümet desteği vardır.

\subsubsection{Seul}

Seul 1990'ların sonlarından bu yana geniş bantlı interneti başarılı şekilde kullanmaktadır ve tarih boyunca her zaman bağlantılı kentlerin iyi bir örneği olmuştur. Seul Büyükşehir Hükümeti (SMG), 1990'larda e-Hükümet programını başlatmıştır. Gelişmenin ilk aşamaları hükümet veri tabanlarının oluşturulmasına, internet üzerinden kamu hizmetlerinin ve bilginin sağlanmasına ve BİT altyapısının geliştirilmesine odaklanıyordu. 2011'de SMG vatandaşların mobil cihazlarından hükümet hizmetlerine ve bilgilerine ücretsiz erişmesini sağlamak için bir Wi-Fi ve kapalı devre televizyon (CCTV) ağından oluşan yüksek hızlı telekomünikasyon ağını tamamladı.

Kore'de U-kent yani her zaman her yerde olan kent olarak da bilinen akıllı kent, daha verimli bir iletişim, ulaşım ve doğal kaynaklar konseptine dayalı yeni bir sürdürülebilir ekonomi modeli olmayı hedeflemektedir. Bu tür kentler, her zaman her yerde olan bilgi teknolojisini yönetir. Kentte çalışan tüm bilgi sistemleri birbirleriyle bağlantılıdır ve neredeyse her şey kablosuz ağ gibi teknolojilerle bir bilgi sistemine bağlıdır.

Seul, akıllı teknolojilere ilk yatırım yapan şehirler arasındadır. Yıllar boyunca hükümet, akıllı şehrin ihtiyaç duyduğu doğru altyapıyı, örneğin akıllı sensörleri, geniş bant ağını ve fiber optiği elde etmek için çok para harcamıştır. Bugün Seul, dünyadaki en iyi bağlantılı şehirlerden biri ve teknolojik olarak en gelişmiş ülkelerinden birinin başkentidir. Seul enerji, ulaştırma, binalar, yönetim ve sosyal altyapı alanlarında akıllı teknolojileri kurmuştur.

Seul'un gelecek on yılda, vatandaşların refahı ve tüketicilerin gizli bilgilerinin siber saldırılara karşı korunması anlamında daha donanımlı bir şekilde akıllı kent projelerine odaklanması beklenmektedir.

\subsubsection{Barselona}

Dünyanın turizm başkentliğinden mobil teknoloji ve akıllı kent başkentliğine geçiş Barselona’nın öyküsünü bizler için çok değerli kılmaktadır. Akıllı kent tanımı yapılırken üretken bölgeleri olan, günlük yaşam ritmiyle uyumlu, çevreye dost, yeniden doğallaştırılmış, enerji bakımından kendine yeten ve emisyon oranı sıfırlanmış, birbirine bağlanmış birimlerden oluşan metropol alanda yüksek hız sunan bir kent haline gelmek amaçlanmıştır.

Hükümetteki değişiklik, Barselona'nın Akıllı Kent projesini duraklatmış; bu da Akıllı Kent değerini yurttaşlara aktarma ve idari geçişlere rağmen proje devamlılığının sağlanması ihtiyacını göstermiştir. Barselona'nın kamuözel sektör ortaklık modelleri, satıııların açık sistemleri ve standartları benimsemeye ve yeni iş modellerini keşfetmeye istekli olduklarını göstermiş̧ir. Barselona, 1992 Yaz Olimpiyatları ve Mobil Dünya Kongresi gibi uluslararası etkinlikleri kullanarak sürekli dönüşüme uğramış ve 21. yüzyıl ekonomisini sürdürecek mali yatırımları çekmiştir.

\subsubsection{Berlin}

Berlin, hızlı kentleşme zorluklarını aşmak için ulaşım, enerji, sağlık, altyapı ve binalar için akıllı çözümler geliştirmek zorundadır. Berlin'in nüfusunun 2030'a kadar en az 500,000 artması beklenmektedir, bu da Berlin'i akıllı çözümlere yatırım yapmak için teşvik etmektedir. Berlin, akıllı kent olarak gelişmesi için benzersiz 
özelliklere sahiptir: Berlin, Almanya'nın başkenti, en büyük şehri ve en büyük siyasi, sosyal ve kültürel merkezidir. Ar-Ge faaliyetlerine ve büyük ölçekli kentsel gelişim projelerine yaklaşık $€ 1.5$ milyar harcanmaktadır.

Sınırlı kaynakların kullanımının azalması, yenilenebilir enerjilerin kullanımının yerleşmesi, 2050'ye kadar Berlin'in kaynak verimliliğinde ve iklim nötralizesinde artış, yoğun nüfuslu bir kentsel ortamda yaşamanın olumsuz etkilerinin en aza indirilmesi, 'Berlin Akıllı Kent Stratejisi'nin başlıca hedefleridir.

Berlin, akıllı kent uygulamalarını (akıllı yönetim, akıllı ulaşım gibi) demografik değişim, sosyal entegrasyon, kaynak verimliliği , vb. gibi sektörler arası konulardan doğan sorunlarla mücadele etmek için de kullanmaktadır. Berlin, kentin inovasyonlarını tanıtmak, küresel uzmanlarla yuvarlak masa tartışmaları yapmak ve model projeleri sunmak için Metropol Kentler Çözümler Kongresi gibi uluslararası etkinliklere ev sahipliği yapmaktadır. Berlin, hep birlikte iyiye ulaşmak ve vatandaşlarının ihtiyaçlarını karşılamak için hükümet, sektör, hizmetler, özel şirketler gibi 100'den fazla önemli aktörü ve 300'den fazla araştırma grubunu içeren bir Akıllı Kent ağı kurmuştur.

\subsubsection{San Francisco}

San Francisco, vatandaş nüfusu ve iş dünyası ile teknoloji ve sürdürülebilirlik alanında küresel liderdir. Kent, gelir eşitsizliği, uygun fiyatlı konut, işe gidip gelme süreleri ve iklim değişikliği alanında sorunların üstesinden gelmek için yoğun çaba göstermektedir.

Teknoloji alanında öncülüğü destekleyen birden fazla hükümet kurumunun yanı sıra aktif bir vatandaş topluluğunun var oluşu akıllı kent hedeflerine ulaşmayı kolaylaştırmaktadır. San Francisco güçlü bir teknolojik altyapıyı geliştirdikçe, gelecek nesil akıllı kent gelişiminin ön saflarında olmaya hazır durumdadır. San Francisco güçlü bir akıllı kent altyapısına sahiptir ama bunu başarmak, birçok paydaşın beklediğinden daha uzun zaman almıştır.

\subsubsection{New York}

New York, akıllı kent olmayı proaktif şekilde hedeflememekle birlikte, daha fazla karşı karşıya kaldığı büyüyen sorunların üstesinden gelmek ve hedeflerine ulaşmak adına akıllı teknolojileri mümkün olan yerlerde kullanmaktadır.

New York'un önceliği, artan nüfus, ekonomik büyüme, eşitsizlik, altyapı gereksinimleri ve iklim değişiklikleri üzerinde yoğunlaşmıştır. Kent akıllı teknolojileri yalnızca bu önceliklere hitap etmek gereken durumlarda kullanmaktadır. New York, vatandaşlarına değer vermekte, 311 gibi güçlü kent hizmeti girişimlerini uygulamakta ve nüfusunu değisşen dünyaya adapte etmek adına onları eğitmektedir. Kamu fonları şehrin küçük girişimlerini finanse ederken, en önemli Akıllı Kent yatırımlarından bazıları, Hudson Yards, Citibike, ve LinkNYC gibi özel fonlarca yapılmaktadır.

\subsubsection{Gujarat (GIFT)}

"GIFT Şehrinin vizyonu, küresel kriterlere uygun bir Entegre Kent için yeni bir format geliştirmek, hızlı geliştirme ve uygulama için bir yol haritası önermek, uzak gelecek için şehri her açıdan ölçeklendirilebilir hale getirmek, hızlı değişen yaşam tarzlarından ve yeni teknolojilerden kent formatını üretmek, modern teknolojilere ayak uydurabilen bir Küresel Kent imajına ulaşmak gibi hedeflerle gerçekleştirilmektedir.

Gujarat, 2020'ye kadar dünyanın önde gelen finans merkezlerinden biri olmak için New York, Londra, Singapur ve Hong Kong gibi kentlerin attıkları adımlarını izlemek ve onlarla yarışmak istemektedir. GIFT' in 500.000 doğrudan, 500.000 de dolaylı istihdam sağlaması beklenmektedir, bu da ofis ve konut alanı olarak 5,76 milyon metre karelik emlak gerektirmektedir. GIFT, çeşitli güçlü yönlerine dayanarak oluşturulacak iş firsatlarından \%68 oranında bir pay kapmayı planlamaktadır. GIFT, Mumbai' ye yakın konumu ve havayolu ve karayolu ile güçlü bağlanabilirliği sayesinde güçlü bir konum avantajına sahiptir.

GIFT şehri, finansal BİT ve BİT kullanan Servislerin önde gelen varış noktalarından biri olma hedefiyle küresel bir finans merkezi olmayı amaçlamaktadır. Bu nedenle büyük oranda finans sektörünün büyümesini ve kentin çıktılarını destekleyecek teknolojik altyapıyı inşa etmeye odaklanmaktadır. Karayolları, su ve elektrik anlamında akıllı şehrin önerileri, Şikago veya Barselona gibi diğer önde gelen akıllı kentlere kıyasla daha az gelişmiştir. Kentde, her tür topluluğun canlanması için gerekli olan okul, hastane, banka, vb. gibi her tür sosyal altyapı bulunacaktır. Aynı zamanda GIFT şehrindeki vatandaşlar, küresel standartlarda ve hatta daha üzerinde yüksek hızlı internet bağlantısına erişebilecektir. 


\subsection{Başarılı Bir Dönüşüm İçin Atılması Gereken Adımlar}

Akıllı kent dönüşümünde atılması gereken adımlar;

1. Kente özel vizyon, hedef ve stratejinin belirlenmesi,

2. Önceliklerin tanımlanması,

3. Alt hedeflerin belirlenmesi,

4. Projelerin tanımlanmasi,

5. Finansman modelinin belirlenmesi,

6. Değer zinciri analizi,

7. Paydaş haritasının belirlenmesi,

8. Hukuki boyutların incelenmesi,

9. İyi uygulamaların analizi,

10. Teknoloji platform modeli,

11. Proje yönetim ofisi ve yol haritası,

12. İletişim planı

oluşturulması şeklinde sıralamak mümkündür.

\section{SONUÇ}

Artan nüfus, çarpık kentleşme, artan beklenti ve azalan doğal kaynaklar, kentleri yaşanmaz yerler haline getirmiştir. Başta trafik ve park yeri olmak üzere ulaşım sorunları, temiz suya erişim, güvenlik, hijyen gibi temel insani ihtiyaçların karşılanması ve üstelik sürdürülebilir bir biçimde karşılanması için yenilikçi ve akılcı çözümlere her zamankinden daha çok ihtiyaç duyulmaktadır.

$\mathrm{Bu}$ ihtiyacın karşılanabilmesi adına gündeme gelen çözüm önerilerinden birisi de, hiç kuşkusuz akıllı kent yaklaşımıdır. "Bilişim teknolojilerinden yararlanılarak kent varlıklarını ve kaynaklarını bütünleştiren kentsel gelişim vizyonu ve her kentin kendi ihtiyacına göre şekillenen bir yolculuk" olarak tanımlanan akıllı kent kavramının son yıllarda ülkemizde de son derece popüler bir hal aldığı görülmektedir.

Popüler, moda veya gelip geçici bir heves olarak bakılmasının pahalıya mal olacağı akıllı kent uygulamaları, son derece yüksek maliyetli yatırımlardır. Sosyal sermaye ve etkin bir katılım gerektiren "akıllı kentler" konusunda; nesnel gerçeklerden ve bilimsellikten uzak yaklaşımlar ve/veya aceleci kararlarla başarılı olabilmek, üstelik gerekli finansman bulunsa dahi, mümkün değildir.

$\mathrm{Bu}$ çalışmada; hedefini gerçekleştirmiş akıllı kentlerle, bu kentlerde başarılı olmuş uygulamalar incelenerek ülkemize nasıl uyarlanabileceği konusunda eleştirel bir perspektif sunulmaya çalışılmıştır.

Dünyadaki başarılı olmuş akıllı kentler incelendiğinde, her birinin kendi ihtiyacına göre şekillenen özgün bir öyküsünün olduğu, koşullara göre şekillenen bir yolculuk sonucunda belirledikleri hedefe ulaştıkları görülmektedir. İncelenen başarı hikâyelerinden, ülkemizde sıklıkla görmeye alıştığımız tek merkezden (Ankara) yönetilmeye çalışılan toptancı bir anlayışla istenen hedeflere ulaşılamayacağı, sürdürülebilir bir başarı için her kentin önceliklerini, güçlü ve zayıf yönlerini dikkate alan, kente özgü yaklaşımların belirleyici olduğu görülmüştür.

Kentin verili durumu, kapasitesi, güçlü ve zayıf yanları ve öncelikleri dikkate alınarak katılımcı bir anlayışla gerçekçi bir kent vizyonu oluşturularak çalışmalara başlanılmalıdır. Vizyon belirlenirken görülmek, duyulmak istenmeyen gerçeklerin de dikkate alındığ , hamasetten uzak, bilimsel bir tutum benimsenmesi, istenilen hedefe varılması için hayati öneme sahiptir. Çünkü tüm planlama, belirlenen vizyon sonrasında konulan hedefe varmak üzere yapılacaktır.

Yapılan işin teknolojik araçlarla yapılıyor olması nedeniyle akıllı kentin bir teknolojik ürün olduğu yanılgısına asla düşülmemelidir. İncelenen sayısız örneğin gösterdiği gibi iş sonunda insan ve onun zihniyetinde bitmektedir. En son teknolojiler kullanılıyor da olsa nihayetinde teknolojinin bir araç olduğu aslolanın yani amacın insan olduğu asla unutulmamalıdır.

Çalışmamız kapsamında incelenen Kopenhag, Barselona, Seul, Singapur, Berlin, New York, Londra, Gujarat, San Francisco gibi kentlerin başarı öyküleri incelendiğinde insanı merkeze alan, finansal açıdan sürdürülebilirliği önceleyen yaklaşımların başarılı olması yukarıda öne sürdüğümüz tezi doğrulayan önemli bir göstergedir. Bilinen bu iyi örneklerin dışında odağında insanın değil teknolojinin yer aldığı, başarıya ulaşamamış sayısız örnek de yine bu yaklaşımı doğrular niteliktedir. 
Başarılı bir akıllı kent uygulamasının temelinde; tekil teknolojik çözümlerden ziyade bütünsel bir bakış açısıyla odağına insanı alan, gerçek zamanlı veri akışılla beslenen Coğrafi Bilgi Sistemi uygulamaları olduğu görülmektedir. Akıllı Kent iddiasından söz edebilmek için ilk olarak o kentin Coğrafi Bilgi Sistemi altyapısını tamamlamış olması gerekmektedir. Ülkemizin 30 yıla varan CBS macerasında istenilen seviyeye varamamış olması gerçeğiyle bir an önce yüzleşilmeli ve geciken adımlar bir an önce atılmalıdır. Günün modası olarak markete sunulan Akıllı Kent kavramının; aslında gerçek zamanlı büyük verinin bilgiye dönüştürüldüğü bir tür Coğrafi Bilgi Sistemi olduğu gözden kaçırılmamalıdır.

Başarılı bir Akıllı Kent için ilk olarak coğrafi bilgi altyapısını tamamlanmalı, çıkış noktası ve varılmak istenen hedefin kentte yaşayan insanın mutluluğu ve refahını arttırmak olduğu unutulmadan, teknolojideki gelişmeler göz ardı edilmeden gerçekçi ve uygulanabilir bir sistem kurgulanmalıdır.

Kentteki mevcut ve gelecekteki tüm sistemleri kapsayan "sistemlerin sistemi” olması, kent düzeyinde tüm paydaş ve bileşenlerin birlikte çalışmasını zorunlu kılmaktadır. Ülkemizde birlikte çalışma kültürünün gelişmemiş olması, akıllı kent uygulamaları için önemli sorunlardan biri olarak görülmektedir. Bu sorunu aşmak için yetki ve sorumluluklar net bir biçimde tanımlanmalı hiçbir boşluk bırakılmamalıdır.

Başarılı akıllı kent örneklerinin tamamında, yönetsel yeterliliğe ve yaptırım gücüne sahip bir organizasyonun önderlik yaptığı, lokomotif görevi üstlendiği görülmekte olup; ülkemizdeki yetki dağılımının iç içe geçmiş ve yaptırımların belirsiz, yetersiz olması gibi olumsuzlukların da ciddi bir risk oluşturduğu değerlendirilmektedir.

Akıllı kent idealinin başarıya ulaşmasındaki temel taşıyıcılardan olan sivil toplum örgütleri ve vatandaş katılımı gibi sosyal sermaye unsurları bakımından zengin bir ülke olmayışımız planlamada samimiyetle ortaya konulmalıdir.

Yerel sorunlarımızın dışında başta yüksek ilk yatırım maliyeti ve finansal sürdürülebilirlik gibi pek çok evrensel zorluğun üstesinden gelinmesiyle başarıya ulaşılabilecek bir hedef olan akıllı kent ideali için, hamasetten uzak bilimsel ve nesnel bir yaklaşım benimsenmelidir. Bilimsellikten ve nesnellikten uzak yaklaşımların yatırımların boşa gitmesinin yanında Akıllı Kent kavramın içini boşaltacağı ve itibarsızlaştıracağı gerçeği de unutulmamalıdır. Sayısız potansiyel risk ve soruna açık olmasına karşın, dünyada pek çok başarılı uygulaması olan akıllı kentler idealine ülkemizde de ulaşabilmek için; bir an önce Coğrafi Bilgi Sistemi altyapısı kurulmalı, tekil teknolojik çözümler yerine birbirini tamamlayan bütüncül ama özgün yaklaşımlar ve insan odaklı bir anlayış egemen kilınmalıdır.

\section{KAYNAKLAR}

Chourabi, H. Nam, T., Walker, S., Gil-Garcia, J. R., Mellouli, S., Nahon, K., Pardo, T.A. ve Scholl, H.J. 2012, "Understanding Smart Cities: an Integrative Framework", In 45th Hawaii International Conference on System Sciences, 4-7 January Maui, HI, s. 2289-2297.

İTÜ Vakfı Dergisi, 2017, Sayı 77 İstanbul, 129 Sayfa

Türkiye Bilişim Vakfı, 2016, Akıllı Şehirler Yol Haritası İstanbul, 158 Sayfa

Kalkınma Bakanlığı, 2013, Bilgi Toplumu Stratejisinin Yenilenmesi Projesi, Şubat 2013

Ulusoy M, 2017, Akıllı Şehirler, Yüksek Lisans Tezi, İstanbul Bilgi Üniversitesi, 2017

Harrison, C.- Eckman, B.- Hamilton, R.- Hartswick, P.- Kalagnanam, Jayant Ramarao- Paraszczak, JurijWilliams, P. 2010. Foundations For Smarter Cities,IBM Journal of Research and Development,

İBB, 2016, Akıllı Şehirler Müdürlüğü Akıllı Şehirler Çalıştayı, 2016 (Frost \& Sullivan)

Kethani A., Marwali M., 2011, “Smart Power Grids”, Springer.

A.B.M. Shawkat Ali, 2013 , "SMART GRIDS Opportunities, Developments and Trends”, Springer.

Boren, T. \& Young, C. 2013, Getting creative with the 'creative city'? towards new perspectives on creativity in urban policy. International Journal of Urban and Regional Research, 37 (5), 1799-1815.

Anttiroiko, A.V. ve ark. 2013, Smart cities in the new service economy: building platforms for smart services, $\mathrm{Al}$ \& Society, 1-12. Fortcoming Retrieved: 05/05/2014, http://link.springer.com/article/10.1007\%2Fs00146-0130464- 